\title{
Safety Pathway Design for Patients Not Affected by COVID-19 During the SARS-CoV-2 Pandemic in an Italian University Hospital
}

This article was published in the following Dove Press journal:

Risk Management and Healthcare Policy

\author{
Emma Montella' \\ Emanuele Mario Caputi ${ }^{1}$ \\ Mariapia Del Core' \\ Antonella Guida ${ }^{2}$ \\ Maria Triassi' \\ 'Public Health Department, "Federico II" \\ University of Naples, Naples, Italy; \\ ${ }^{2}$ Health Management, Local Health \\ Authority (ASL) Caserta, Caserta, Italy
}

Correspondence: Emma Montella

Public Health Department, "Federico II"

University of Naples, Via Sergio Pansini, 5,

Naples 8013I, Italy

$\mathrm{Tel}+393332253185$

Email emma.montella@unina.it

\section{Introduction}

Cases of pneumonia of unknown etiology were identified in the city of Wuhan, the most populated city in central China, late in December 2019. On January 7, 2020, the virus responsible for this condition was defined as Coronavirus 2 Acute Respiratory Syndrome (SARS-CoV-2); on February 11, the World Health Organization announced that the respiratory disease caused by the new coronavirus was called COVID-19. COVID-19 is a potentially fatal disease whose spread has reached epidemiological criteria to be declared a pandemic, having infected, according to WHO Coronavirus Disease Situation Reports, over 100,000 people in more than 101 countries. This new public health emergency is challenging the economy, the medical field and public health infrastructures. Health-care systems worldwide have had to adapt their processes to face this new situation and attempt to provide a global response, and countries that have already experienced the emergency have a lot to teach.

According to the "Situation Update Worldwide" Report of the European Centre for Diseases Prevention and Control (ECDC), Italy was one of the first countries to be affected, with 3896 confirmed cases and 148 deaths as of March 5, 2020. Considering the number of people affected, that human-to-human transmission is the main route, through droplets, and that treatment protocols and a vaccine are still being developed, the spread of the infection can be limited only by quarantine protocols. ${ }^{1}$ Therefore, on March 8 , the Italian Government implemented extraordinary measures, such as the restriction of free movement of people and social activities, to limit the viral transmission. The decision was crucial albeit insufficient. ${ }^{2}$ The Italian National Health System, one of the globally best organized health-care systems, has had to reorganize its health-care procedures. Hospital facilities effectively responded to the demands of infected patients: by March 30, as many as 27,795 symptomatic people were hospitalized in Italy, among whom were 3,981 patients in intensive care units. ${ }^{3}$ At the same time, there was need to ensure provision of health care to patients not infected by COVID-19 but presenting other diseases requiring health-care services that could not be postponed.

The Federico II University Hospital in Naples was able to reach that target by establishing a Crisis Management Unit, made up of the following experts: (i) The 
General Manager and the Administrative Director to handle political, legal, administrative and economic aspects; (ii) the Medical Director to deal with Health Management; (iii) the Director of the Public Health Department; (iv) the Risk Manager to oversee clinical and non-clinical risk; (v) the Director of the Infectious Diseases Department; (vi) the Director of the Intensive Care Department; (vii) the Director of the Mother-Child Department; (viii) the Director of the Pediatric Infectious Diseases Department; (ix) the Nursing Officer; (x) the Head of Emergency Nursing Officer; (xi) the Head of the Hospital Pharmacy and Pharmacology for drug choices and supply; (xii) a Biomedical Engineer for equipment management; (xiii) a Structural Engineer for structural works. This multidisciplinary approach allowed the University Hospital to face structural, management (e.g. surge capacity and capability, human resource management, as well as patient and staff risk management) and clinical issues (e.g. treatment protocols and assurance of integrated health care requiring continuity).

The Crisis Management Unit has reorganized its health-care processes, developing two separate pathways dedicated to COVID-19 and non-COVID-19 patients, to be able to meet epidemiological needs all the while ensuring safe health care for all patients.

The plan was active from March 9 to May 4 - i.e. corresponding to the lockdown period in Italy, and provided extreme measures including: (i) closure of hospital departments that provided deferrable health-care services (Departments of Internal Medicine, Endocrinology, Cardiology, Gastroenterology, Neurology, Physiatrics, Occupational Medicine, Immunology, Psychiatry, Dermatology); (ii) restricting visitor access to hospital; (iii) dedicated patient transport and isolation pathways; (iv) interruption of elective surgery - continuing only emergency and selected oncological surgical procedures. In this study, we describe the safety pathways developed to provide health care during the pandemic, to patients not infected with COVID-19, needing specialized health care and who could not be addressed to other regional hospitals because of their specialized health-care demands. Indeed, "Federico II" University Hospital provides the following highly specialized health-care services in terms of both surgery and clinical care: (i) Neurosurgery; (ii) Cardiac surgery; (iii) Thoracic surgery; (iv) Maxillofacial surgery; (v) Ophthalmic surgery; (vi) Rare diseases; (vii) Pediatrics; (viii) Child Psychiatry; and (ix) Gastroenterological emergency.

The aim of the present study is not to describe the sensibility and specificity assessment in reporting
COVID-19 cases, but rather to describe the safety pathways set up for patients not affected by COVID-19, during the SARS-CoV-2 pandemic, thus ensuring health care in a safe working environment.

The description of the safety pathways enacted and our findings might be useful to other health-care workers, and to national and regional policymakers involved with human resource and technological management, in view of a possible second wave of the pandemic.

\section{Methods}

Considering that asymptomatic or pre-symptomatic patients might be undetected infection vectors, according to our safety protocol, all patients, before their access to the facilities, undergo (i) pre-admission audit and (ii) preadmission screening.

Pre-admission audit is performed via telephone for all patients, through the completion of a form (Figure 1). The form includes standard questions, investigating the epidemiological and clinical context, ${ }^{4}$ since to promptly identify infected patients and prevent further infection spread, health workers need to be aware of the patient's travel history or of any contact with suspected cases. The simultaneous presence of one epidemiological and one clinical criterion identifies a patient at risk. In such a case, the patient cannot access the facility, and the clinical or surgical care procedures required are rescheduled, with a procedure that includes a follow-up program at 5-day intervals. Finally, in the absence of a notification of SARS-CoV-2 infection, the patient is scheduled for a new visit, and a new pre-admission audit. In a case of positive diagnosis, instead, the procedure for SARS-CoV2 positive patients will be followed.

In the absence of epidemiological and clinical risk criteria, the patient is asked to attend the facility, accessing through an independent and isolated screening area, outside the building. In this area, each patient is guided from the entrance to the exit, so as to move only forward and avoid any contact with other patients. In addition, nonhealth-care professionals are instructed to provide all patients with a surgical mask and a hand sanitizer kit.

Patients undergo thermal screening by health-care personnel, followed by a rapid serological test for IgG and IgM antibodies if their body temperature is below $37.5^{\circ} \mathrm{C}$. The result of the test is available in 4 minutes, during which the patient is asked to wait in the same room where the test was executed. The test kits used are Screen COVID-19 IgM/IgG from Screen Italia, characterized by $85 \%$ sensitivity and $96 \%$ specificity for IgM and 100\% sensitivity and 98\% specificity 


\section{PREADMISSION AUDIT FORM}

SURNAME NAME DATE OF BIRTH

TRIAGE DATE DATE SUPPOSED ADMISSION

PART A: Does he/she have one of following symptoms?

- Temperature YES NO

- Cough YES NO

- Respiratory distress YES NO

PART B: Does he/she have the following exposures during the last 14 days?

- Close contact with COVID-19 suspected/confirmed cases

- Cohabitant of COVID-19 suspected/confirmed cases

- $\quad$ Travelling with COVID-19 suspected/confirmed cases

- Providing care to COVID-19 suspected/confirmed cases
YES NO

YES NO

YES NO

YES NO

PART C: Does he/she have the following exposures during the last 14 days?

- Travel from /resident in China

YES NO

- $\quad$ Travel from /resident in Italian COVID-19 restricted area*

YES NO

\section{$L E G E N D$}

If one YES in PART A and one YES in PART B or C: the patient is COVID-19 suspected case. Alert 118 (Emergency Service) to direct patient to COVID-19 management centre.

If one YES in PART B: the patient must be isolated on his home and checked by regional Epidemiology and Prevention Service.

If one YES in PART C: the patient must be isolated on his home and checked by regional Epidemiology and Prevention Service.

If one YES in PART A: the patient is not COVID-19 related and have to be managed according to his/her clinical condition.

\section{References:}

CM Ministero della Salute 27.02.2020.

CM Ministero della Salute 01.03.2020.

Ordinanze Regione Campania n. 1 del 24.02.2020

Ordinanze Regione Campania n. 3 del 26.02.2020

Ordinanze Regione Campania n. 4 del 26.02.2020

Figure I Preadmission audit form.

for IgG. The test is performed according to the manufacturer's instructions. If a patient tests negative, access to the facility for the medical examination or hospital admission is enabled through the designed safety path. Otherwise, she/he is directed to a dedicated isolation room, equipped with negative pressure ventilation, to undergo a nasopharyngeal/ oropharyngeal (OP) swab test for SARS-CoV-2 by reverse transcription-polymerase chain reaction (RT-PCR), the result of which is ready in 30 minutes. Only if negative is the patient allowed to access the health-care services; otherwise, in the event of a SARS-CoV-2 positive swab, the patient re- enters via the COVID-19 pathway. Similarly, patients with body temperature $>37.5^{\circ} \mathrm{C}$ are directed to a specialized infectious disease consultation and, possibly, chest CT, before accessing the path described.

Within the independent and isolated screening area, containment measures and good practices are complied with, ensuring the use of PPE and the availability of hydro-alcoholic gel for handwashing, according to ECDC "Infection prevention and control for COVID-19 in healthcare settings". All areas are correctly sanitized and ventilated after every access. ${ }^{5}$ 


\section{Results and Discussion}

From March 9 to May 4, 2020, we completed 3263 preadmission audits; among these, 2587 patients were eligible for admission (Table 1-A), while the remaining 676 patients were tested every 5 days, until they were allowed to preadmission screening. Among the 2587 patients, 64 (2.47\%) had a body temperature equal to or above $37.5^{\circ} \mathrm{C}$ and 2523 $(97.53 \%)$ had a body temperature below $37.5^{\circ} \mathrm{C}$. The 64 patients with temperature equal to or above $37.5^{\circ} \mathrm{C}$ were directed to infectious disease counselling and chest CT, if necessary; among these, 60 patients $(93.75 \%)$ were found not to be affected by COVID-19 and were directed to the non-COVID-19 patients safety pathway, while $4(6.25 \%)$ were diagnosed as having COVID-19 and followed the COVID-19 safety pathway.

The 2523 patients with body temperature below $37.5^{\circ} \mathrm{C}$ underwent rapid serology testing (Table 1-B). Of these, 83 (3.29\%) tested positive and subsequently underwent OP swab. The swabs confirmed three SARS-CoV-2 positive cases. At the end of the observation period, as many as 2587 medical services were provided within the nonCOVID-19 patient pathway - including both specialized surgery and clinical care, 1720 medical services (66.49\%) for oncology treatment in oncology and hematology units, 63 $(2.43 \%)$ for dialysis units, $516(19.94 \%)$ for gynecology units, 208 (8.05\%) specialized surgery, 80 (3.09\%) for cardiovascular emergencies and cardiac surgery units.

The accomplishments of our University Hospital in relation to the non-COVID-19 patients pathway, at the end of the lockdown period, are an expression of appropriateness and efficacy of the safety procedures enacted. Although the two screening procedures of the pathway described have controversial sensibility, specificity and appropriateness, they are nevertheless characterized by rapid execution, ${ }^{6}$ and allowed us to achieve our target of delivering medical care. Indeed, the aforementioned tools allowed access to the facilities during the observation period only of seven patients affected by COVID-19, four of whom were identified in the pre-admission screening and three who were positive at the serological rapid test and confirmed positive at the OP swab (Table 1-C).

The audit and screening pre-admission procedures are not specific to individual risk assessment or relevant to the choice of whether to provide or delay health care. In detail, the preadmission audit is an imperfect barrier to virus spread, due to: (i) the rapid variations in the epidemiological and clinical criteria used in the survey form, related to the epidemiological evolution of the disease; (ii) absence of detectable symptoms (clinical risk factors) during the incubation period; (iii) symptoms variability during the symptomatic phase; (iv) imperfect performance of the personnel who carry out the screening procedure; (v) active evasion of screening by the interviewees. However, the pre-admission audit has proven useful because it is structured in an easy-to-use form, with concise and appropriate indicators and can be administered to patients by nonspecialized health-care workers.

Regarding the pre-admission screening, on the other hand, thermal scanning is insufficient as a diagnostic criterion for COVID-19; however, it is rapid and does not require direct patient-operator contact. Rapid serology testing is not a diagnostic tool, ${ }^{7}$ but its use allowed us, affordably and without need for specialized personnel, to detect 83 suspected cases, guaranteeing a balance between speed and safety in the health-care pathway. Although rapid serological tests do not result in a significant containment of infection among the population, their use has proven helpful to limit in a short time the risk of having infected patients within the hospital.

The key points of the safety pathway include: (i) preadmission audit of patients scheduled for visits to continue to meet their specialized care needs; (ii) confinement of patients outside the building for pre-admission screening, avoiding contamination of the facilities; (iii) body temperature measurement and availability of hydro-alcoholic gel for hand washing and PPE to all patients, guaranteeing compliance with standard prevention measures to reduce infection transmission; (iv) isolation of patients positive to rapid serology testing, in order to limit transmission from patient to health-care workers; (v) PPE for patients and health-care professionals; (vi) management of clinical and non-clinical risk for health-care workers: indeed, the infection rate among health-care workers in the observation period was $2.14 \%$, well below the national average, which was $11 \%$; (vii) continuity of health care to patients not infected with COVID-19. Absenteeism rates among workers did not vary during the pandemic, compared with the rates detected during the same period in 2018 and 2019. Although this comparison is only local, the lack of variation is quite encouraging in terms of efficacy of the model adopted.

\section{Conclusion}

The SARS-CoV-2 pandemic outbreak required a remodelling of the health-care systems to ensure the best possible medical care for the population. In this scenario, it was essential to 
Table I Characteristics of Patients Undergoing Pre-admission Screening, Rapid Serology Testing and Nasopharyngeal Swab

\begin{tabular}{|c|c|c|c|c|c|c|}
\hline \multicolumn{7}{|c|}{ A. Patients Undergoing Pre-admission Screening by Department Unit } \\
\hline $\begin{array}{l}\text { Hospital } \\
\text { University } \\
\text { Department/Unit }\end{array}$ & $\begin{array}{l}\text { Oncology } \\
\text { and } \\
\text { Hematology }^{\mathrm{a}}\end{array}$ & Dialysis $^{\mathbf{a}}$ & Gynecology $^{a}$ & $\begin{array}{l}\text { Specialized } \\
\text { Surgeries }^{\mathbf{a}}\end{array}$ & $\begin{array}{l}\text { Cardiovascular } \\
\text { Emergencies Care and } \\
\text { Cardiac Surgery }^{\mathrm{a}}\end{array}$ & Total $^{\mathbf{b}}$ \\
\hline Patients & $1720(66.49 \%)$ & $63(2.43 \%)$ & $516(19.94 \%)$ & $208(8.05 \%)$ & 80 (3.09\%) & $2587(100 \%)$ \\
\hline Female & $1093(63.55 \%)$ & $31(49.21 \%)$ & $516(100 \%)$ & $87(41.83 \%)$ & $30(37.5 \%)$ & $1757(67.92 \%)$ \\
\hline Male & $627(36.45 \%)$ & $32(50.79 \%)$ & $0(0 \%)$ & $12 \mid(58.17 \%)$ & $50(62.5 \%)$ & $830(32.08 \%)$ \\
\hline Age $18-20$ & $3(0.17 \%)$ & $0(0 \%)$ & $355(68.80 \%)$ & $2(0.96 \%)$ & $0(0 \%)$ & 360 (13.92\%) \\
\hline Age $21-40$ & I 34 (7.79\%) & $4(6.35 \%)$ & 140 (27.13\%) & $28(13.46 \%)$ & $6(7.5 \%)$ & $312(12.06 \%)$ \\
\hline Age $4 I-60$ & 663 (38.55\%) & $19(30.16 \%)$ & 19 (3.68\%) & $64(30.77 \%)$ & 30 (37.5\%) & 795 (30.73\%) \\
\hline Age $\geq 6 \mathrm{I}$ & 920 (53.49\%) & $40(63.49 \%)$ & $2(0.39 \%)$ & 114 (54.8I\%) & 44 (55\%) & I I 20 (43.29\%) \\
\hline $\begin{array}{l}\text { Patient with } \\
\text { temperature }<37.5^{\circ}\end{array}$ & 1700 (98.84\%) & $55(87.30 \%)$ & $500(96.90 \%)$ & $196(94.23 \%)$ & $72(90 \%)$ & $2523(97.53 \%)$ \\
\hline $\begin{array}{l}\text { Patient with } \\
\text { temperature }>37.5^{\circ}\end{array}$ & $20(1.16 \%)$ & $8(12.70 \%)$ & $16(3.10 \%)$ & $12(5.77 \%)$ & $8(10 \%)$ & $64(2.47 \%)$ \\
\hline \multicolumn{7}{|c|}{ B. Patients Undergoing Rapid Serology Testing by Department Unit } \\
\hline $\begin{array}{l}\text { Hospital } \\
\text { University } \\
\text { Department/Unit }\end{array}$ & $\begin{array}{l}\text { Oncology } \\
\text { and } \\
\text { Hematology }^{\mathrm{a}}\end{array}$ & Dialysis $^{\mathbf{a}}$ & Gynecology $^{a}$ & $\begin{array}{l}\text { Specialized } \\
\text { Surgeries }^{\mathrm{a}}\end{array}$ & $\begin{array}{l}\text { Cardiovascular } \\
\text { Emergencies Care and } \\
\text { Cardiac Surgery }^{\mathrm{a}}\end{array}$ & Total $^{\mathbf{b}}$ \\
\hline Rapid Test & 1700 (67.38\%) & 55 (2.18\%) & 500 (19.82\%) & 196 (7.77\%) & 72 (2.85\%) & $2523(100 \%)$ \\
\hline Negative Rapid Test & 1639 (96.4I\%) & 48 (87.27\%) & 497 (99.4\%) & I9I (97.45\%) & 65 (90.28\%) & $2440(96.7 I)$ \\
\hline Positive Rapid Test & 61 (3.59\%) & 7 (I2.73\%) & $3(0.6 \%)$ & $5(2.55 \%)$ & 7 (9.72\%) & 83 (3.29\%) \\
\hline Female $^{c}$ & $40(65.57 \%)$ & $3(42.86 \%)$ & $3(100 \%)$ & $2(40 \%)$ & $2(28.57 \%)$ & $50(60.24 \%)$ \\
\hline Male ${ }^{c}$ & $21(34.43 \%)$ & $4(57.14 \%)$ & $0(0 \%)$ & $3(60 \%)$ & 5 (7I.43\%) & $33(39.76 \%)$ \\
\hline Age $18-20^{c}$ & I (I.64\%) & $0(0 \%)$ & $0(0 \%)$ & $0(0 \%)$ & $0(0 \%)$ & I (1.20\%) \\
\hline Age $21-40^{c}$ & $5(8.20 \%)$ & I (I4.28\%) & $0(0 \%)$ & $0(0 \%)$ & $0(0 \%)$ & $6(7.23 \%)$ \\
\hline Age $4 I-60^{c}$ & 15 (24.59\%) & I (I4.28\%) & I (33.33\%) & I (20\%) & $3(42.86 \%)$ & 21 (25.30\%) \\
\hline Age $\geq 6 I^{c}$ & $40(65.57 \%)$ & 5 (7I.44\%) & $2(66,67 \%)$ & $4(80 \%)$ & $4(57.14 \%)$ & $55(66.27 \%)$ \\
\hline \multicolumn{7}{|c|}{ C. Patients Undergoing Swab by Department Unit } \\
\hline $\begin{array}{l}\text { Hospital } \\
\text { University } \\
\text { Department/Unit }\end{array}$ & $\begin{array}{l}\text { Oncology } \\
\text { and } \\
\text { Hematology }^{\mathrm{a}}\end{array}$ & Dialysis $^{\mathbf{a}}$ & Gynecology $^{a}$ & $\begin{array}{l}\text { Specialized } \\
\text { Surgeries }^{\mathbf{a}}\end{array}$ & $\begin{array}{l}\text { Cardiovascular } \\
\text { Emergencies Care and } \\
\text { Cardiac Surgery }^{\mathrm{a}}\end{array}$ & Total $^{\mathbf{b}}$ \\
\hline Swab & 61 (73.49\%) & 7 (8.43\%) & $3(3.61 \%)$ & 5 (6.02\%) & 7 (8.43\%) & $83(100 \%)$ \\
\hline Negative Swab & 59 (96.72\%) & 7 (100\%) & $3(100 \%)$ & $4(80 \%)$ & 7 (100\%) & $80(96.38 \%)$ \\
\hline Positive Swab & $2(3.28 \%)$ & $0(0 \%)$ & $0(0 \%)$ & I (20\%) & $0(0 \%)$ & $3(3.62 \%)$ \\
\hline Female $^{d}$ & I (50\%) & $0(0 \%)$ & $0(0 \%)$ & $0(0 \%)$ & $0(0 \%)$ & I (33.3\%) \\
\hline Male $^{d}$ & I (50\%) & $0(0 \%)$ & $0(0 \%)$ & I (100\%) & $0(0 \%)$ & $2(66.7 \%)$ \\
\hline Age $18-20^{d}$ & $0(0 \%)$ & $0(0 \%)$ & $0(0 \%)$ & $0(0 \%)$ & $0(0 \%)$ & I (33.3\%) \\
\hline Age $21-40^{d}$ & $0(0 \%)$ & $0(0 \%)$ & $0(0 \%)$ & $0(0 \%)$ & $0(0 \%)$ & $0(0 \%)$ \\
\hline Age $4 I-60^{d}$ & I (50\%) & $0(0 \%)$ & $0(0 \%)$ & I (100\%) & $0(0 \%)$ & $2(66.7 \%)$ \\
\hline Age $\geq 6 \mathrm{I}^{\mathrm{d}}$ & I (50\%) & $0(0 \%)$ & $0(0 \%)$ & $0(0 \%)$ & $0(0 \%)$ & $0(100 \%)$ \\
\hline
\end{tabular}

Notes: ${ }^{a}$ The percentages are calculated on the total number of patients in the care departments. ${ }^{\mathrm{b}}$ The percentages are calculated on the total number of screened patients. ${ }^{\mathrm{c}}$ The percentages refer to patients positive for rapid serology testing. ${ }^{\mathrm{d}}$ The percentages refer to patients positive for nasopharyngeal swab.

guarantee medical services to the largest number of individuals whether or not affected by COVID-19. The achievement of these objectives, seemingly conflicting in the facilities devoted to COVID-19 patients, was possible through the development of organizational models able to provide safety pathways dedicated to delivery of health services and medical care to COVID-19 affected and notaffected patients. 
As to the organizational models developed by an Italian University Hospital, devoted to the health care of COVID19 patients, our paper describes the specific safety pathway implemented for all patients not affected by SARS-CoV-2 who require continuity of specialized health care during the COVID-19 pandemic, for services that cannot be postponed. Our findings, although related to a single research centre with particular features, could be considered as a safety path performance indicator. The number of healthcare and medical services that cannot be postponed, delivered during the first half of 2020 recorded a slight reduction compared with the first half of $2019(-20 \%)$, without lengthening of the waiting lists - an inevitable consequence in the absence of targeted measures.

The current epidemiological situation represents a huge challenge for hospital facilities, particularly if a second wave of COVID-19 were to occur. The purpose, in such circumstances, is to guarantee safe medical care to all people. Therefore, a detailed description of the safety pathway herein reported is relevant because it can be easily adapted to other health-care centres and used in emergency conditions.

\section{Ethics Statement}

The present study was approved by the University Ethics Committee (Comitato Etico Università Federico II di Napoli), ref No. 243/20, according to national and international guidelines for research on humans.

Informed consent and consent to the processing of personal data was signed from all study participants.
All patients participating in the study were over the age of 18 .

This study was conducted in compliance with the Declaration of Helsinki, latest version.

\section{Disclosure}

The author have no conflicts of interest to declare in relation to this work.

\section{References}

1. Kannan S, Shaik Syed Ali P, Sheeza A, Hemalatha K. COVID-19 (Novel Coronavirus 2019) - recent trends. Eur Rev Med Pharmacol Sci. 2020;24:2006-2011. doi:10.26355/eurrev_202002_20378;

2. Sohrabi C, Alsafi Z, O'Neill N, et al. World Health Organization declares global emergency: A review of the 2019 novel coronavirus (COVID-19). Int $J$ Surg. 2020;76:71-76. doi:10.1016/j. ijsu.2020.02.034.

3. Istituto Superiore di Sanità. Epicentro. Sorveglianza integrale COVID19 in Italia. Case report COVID-19-March 30, 2020; 2020. Available from: http://www.salute.gov.it/imgs/C_17_notizie_4362_0_file.pdf.

4. Jiang F, Deng L, Zhang L, Cai Y, Cheung CW, Xia Z. Review of the Clinical Characteristics of Coronavirus Disease 2019 (COVID-19). J Gen Intern Med. 2020;382:1708-1720. doi:10.1056/NEJMoa2002032

5. European Centre for Disease Prevention and Control (ECDC). Disinfection of environments in healthcare and nonhealthcare settings potentially contaminated with SARS-CoV-2. 2020. Available from: https://www.ecdc.europa.eu/sites/default/files/documents/ Environmental-persistence-of-SARS_CoV_2-virus-Options-for-clean ing2020-03-26_0.pdf.

6. Lee J. COVID-19 screening center: how to balance between the speed and safety? $J$ Korean Med Sci. 2020;35(15):e157. doi:10. 3346/jkms.2020.35.e157

7. Döhla M, Boesecke C, Schulte B, et al. Rapid point-of-care testing for SARS-CoV-2 in a community screening setting shows low sensitivity. Public Health. 2020;182:170-172. doi:10.1016/j.puhe.2020.04.009
Risk Management and Healthcare Policy

\section{Publish your work in this journal}

Risk Management and Healthcare Policy is an international, peerreviewed, open access journal focusing on all aspects of public health, policy, and preventative measures to promote good health and improve morbidity and mortality in the population. The journal welcomes submitted papers covering original research, basic science, clinical \& epidemiological studies, reviews and evaluations,

\section{Dovepress}

guidelines, expert opinion and commentary, case reports and extended reports. The manuscript management system is completely online and includes a very quick and fair peer-review system, which is all easy to use. Visit http://www.dovepress.com/testimonials.php to read real quotes from published authors. 